\section{Result of War affected by Soldier's Stature.}

$I_{N}$ your issue of March I Major-General Warrand denies that the chance of being shot in war depends, ceteris paribus, merely upon the square of the soldier's stature.

He would therefore introduce another factor, the thickness of the body, which presents a target varying in size according to the direction from which the fire comes.

This, however, is unnecessary. The stature alone should be considered, because, for the sake of simplicity, we assume that oblique fire is experienced equally by both armies, and we also assume that all soldiers are of similar build. The assemblage of human targets in each army is therefore proportional in size to the square of the average stature.

The Hydro, Ben Rhydding.

John Hill Twigg.

\section{WHAT IS WHISKEY?}

DURING the last three months readers of the daily Press have from time to time been the recipients of informations concerning the nature of whiskey. Their education must have been somewhat heterogeneous in that what whiskey should or should not be seemed to change each week, in accordance with the witness whose evidence was being reported; perhaps now the so-called whiskey test case is over it will be convenient to place before our readers some of the most important facts brought to light by it.

The borough of Islington began its work in the matter of potable spirits with brandy, and succeeded in practically enforcing for this article of commerce a chemical standard. This standard, as in the case of the one which it has, at any rate for the time, succeeded in establishing for whiskey, is a minimal standard, i.e. brandy must contain at least a certain proportion of so-called compound ethers, and whiskey must, if the judgment in this case be maintained, at least contain a certain proportion of so-called impurities, viz. substances other than ethylic alcohol and water. Before dismissing from our notice the brandy standard, we would emphasise the fact that in the case of brandy a minimal amount of one class of by-product, the individual members of which almost certainly have the same therapeutic effect, is demanded. In the case of whiskey, the Islington magistrate fixed a chemical standard based upon an analytical, not chemical or even therapeutical, entity containing such different substances as compound ethers, higher alcohols, acids, and aldehydes. He further strictly enjoined the kind of apparatus in which whiskey must be produced, and the materials which shall in the two countries producing whiskey be solely used in the mash from which the spirit is to be distilled. The question of a chemical standard for brandy, and the protection which such a standard affords to the public, was thoroughly discussed in NATURE of November 3, I904. The anomaly of having a fixed minimum and no fixed maximum for alcoholic impurities in potable spirits is too palpable to need amplification, and has been definitely recognised by the Belgian authorities, who refuse to allow the sale of a potable spirit possessing a coefficient of impurities of more than 300. This fact is of special interest at the present time, for if the Islington judgment is to stand, no potable spirit can be sold as whiskey which, inter alia, possesses a coefficient of impurities of less than 380 .

To the average reader the judgment containing the definition of what for the future must be sold as Irish and Scotch whiskey would read, and it consists of some five thousand words, as if this question had never been considered before; and, indeed, a leading article upon this subject which appeared in a medical No. 1897 , voL. 737 contemporary last week contained the extraordinary statement that "five years ago there was no suggestion even that potable spirits might be brought within the operation of the Sale of Food and Drugs Act, with a view to the detection of foreign or added spirit." It can scarcely be news to the readers of NATURE that a Select Committee under the chairmanship of Lord Playfair was appointed in I89I to inquire into precisely the same question as was laid before the Islington magistrate, and had at its disposal practically the same material; it examined numerous witnesses, chemical, physiological, and commercial, and reported in $189 \mathrm{r}$.

The best way of criticising Mr. Fordham's judgment is to summarise carefully the conclusions of this committee. At the onset it is a relief to find that upon one point at least they agree, viz. that according to both there is no evidence that any potable spirit sold in the United Kingdom as whiskey contains constituents other than ethylic alcohol which are injurious to health; in other respects we are afraid the Islington magistrate in his judgment is diametrically opposed to the report of this committee. Perhaps the shortest way of dealing with this report in the present article is to quote verbatim the Committee's view with regard to the definition of whiskey.

"Your committee do not attempt a legal definition of whiskey. Whiskey is certainly a spirit consisting of alcohol and water, with a small quantity of bye-products coming from malt or grain, which give to it a peculiar taste and aroma. It may be diluted with a certain quantity of water without ceasing to be whiskey, and it may be diluted with spirits containing little of the bye-products to suit the pocket and palate of customers, and it still goes by the popular name of whiskey. Your committee are unable to restrict the use of the name as long as the spirits added are pure and contain no noxious ingredients." Then again :- "There are varieties in the purity of patent or silent spirits. When they are made for blending it is the object of the distiller to retain a percentage of byeproducts, though to a smaller extent than in pot-still whiskey."

We cannot think that the Islington magistrate was not aware of these conclusions, although it is exceedingly odd that in so lengthy a judgment no mention is made of the report of the select committee. However, the Islington dicta with regard to whiskey are certainly clear. Irish and Scotch whiskey must be produced by the distillation in a pot-still of the wort derived from a mash consisting in Ireland of 75 per cent. barley malt and 25 per cent. indigenous grain, in Scotland of barley malt alone. We are not told what kind of pot-still is to be used, although it is quite clear to anybody who has studied the subject that, with regard to the degree of rectification capable of being produced, pot-stills differ inter se as much as the patent-still differs from the pot. Whether or not the chemical standard of the Islington analyst is also to be maintained is not quite clear, but if so it appears that at least some of the pure malt pot distilleries will have to modify their technique. So far as concerns the actual term whiskey itself, it is not stated definitely that this term, provided it be not prefixed by the epithet Scotch or Irish, should be refused to blended whiskies, that is, to whiskies consist. ing in some part of patent-still or grain spirit, provided they consist of "a very considerable proportion" of pot-still whiskey. If these blended whiskies are to conform to the chemical standard laid down by the Islington analyst, practically all the blended whiskey on the market at the present day will have to undergo a considerable alteration. It is to be noted that, as distinct from the report of the Select Committee, no 
importance is attached by the Islington magistrate to the question of taste or flavour, and no limit is placed by him upon the amount of chemical impurities which whiskey may contain. Although there is scanty reason to believe that the higher alcohols, furfural, and compound ethers in the proportion in which they exist in pot-still whiskey as ordinarily consumed are injurious to health, yet, nevertheless, one cannot view with complaisance a legal definition of whiskey which allows the quantities of these substances to be unlimited. The only safeguard which the public will have will be their own taste. They have shown distinctly what they like in that nine-tenths of the whiskey consumed to-day consists of a blend, with more or less pot-still whiskey, of this same patentstill whiskey, which is to be whiskey no longer, because technologically, if not chemically and dietetically, it diverges too widely from the mediæeval and sentimental "usquebaugh."

Two further points in the judgment of the Islington police magistrate will be of interest to technologists; the first is the absolute condemnation of maize as a constituent of the mash from which whiskey is to be made. This is especially interesting because to those cognisant of the literature of the subject this question of maize as a constituent of brewing and distilling mashes is by no means a new one. Although precedent seems to be no justification at Islington, it is a fact that maize was used as a constituent of distilling mashes previous to $188 \mathrm{x}$. We choose this date advisedly, because in 188 I the use of this same opprobrious maize as a constituent of brewing mashes was by the Free Mash Tun Act actually legalised. Again, the Select Committee on bonded spirits was fully cognisant of the use of maize in distilling mashes, and in its report of $189 \mathrm{I}$ had nothing to say against this grain. Still further, in 1898 the Beer Materials Committee, after a most exhaustive inquiry, refused to prohibit the use of maize. Lastly, the American Pharmacopœia, which includes whiskey as an official preparation of alcohol, specifically states that it may be made from maize. So far as we can gather, the objection to maize is that it cannot be, or at any rate is not, ripened in this country.

The last point which we have space to consider is the statement that, apart from taste and flavour, patent-still whiskey has a different effect upon the consumer from pot-still whiskey. It is true that the therapeutic evidence at present at our command upon this subject is somewhat scanty, but what there is points to the conclusion that practically the only active constituent in whiskey is ethylic alcohol, and that if a given dose of whiskey differs otherwise than in taste and flavour from a proportional amount of pure ethylic alcohol equally diluted, this difference is due entirely to the presence of certain compound ethers. Now as a matter of fact, although patent-still whiskey contains a smaller coefficient of impurities than pure pot-still whiskey, the ethereal moiety of the impurities is approximately the same in both. At any rate, the amount of compound ethers taken in an ordinary dose of patent-still or blended whiskey so nearly approximates to that taken in any ordinary dose of pot-still whiskey that no therapeutical difference is, a priori, to be expected between the two beverages as consumed. The direct evidence we have upon this subject bears out this a priori reasoning.

Over and above the details which have been brought to light in these whiskey prosecutions, everyone must be struck by the curiousness of a legislation which allows disputes of this kind to be decided in a police court. During the past few years many special committees have sat upon subjects relating to the working of the Sale of Food and Drugs Act, and not a few of them have specifically recommended either the institution of a permanent court of reference for these matters or at any rate that they should be laid before some specially organised tribunal. It is sincerely to be hoped that before long these recommendations may be adopted.

\section{THE ROYAL COLI.EGE OF SCIENCE.}

$T \mathrm{HE}$ relation between the University of London and the proposed new Royal College of Science has been the subject of some discussion since the publication of the report of the departmental committee on the college, described in our issue of February 8 (p. 344). It is devoutly to be hoped, however, that the consideration of this matter will not divert attention from the essential point of the committee's report, namely, "that it is desirable that the new institution should be established immediately, and that its organisation should proceed without delay." Divergent views may be held as to the nature of the connection between the University and the new College, but there can be no two opinions as to the folly of delaying the establishment of the institute, as recommended by the committee, while questions of control are being decided.

The subjoined letter from Mr. C. McDermid, hon. secretary to the British Science Guild, appeared in yesterday's Times, and the plea of urgency contained in it is endorsed in a leading article in the same issue.

I am directed by the executive committee of the British Science Guild to request you to be good enough to give publicity to the following expression of the views of the committee on a matter of great national importance.

The departmental committee on the Royal College of Science has shown in its final report that a start can at once be made to provide for the most advanced instruction and research in several branches of applied science, which all are agreed are imperatively necessary in the interests of our national industrial progress.

The danger of delay in giving effect to the recommendations of the departmental committee is recognised by the leaders in science and industry, who are largely represented among the members of the British Science Guild.

The Government have signified their willingness to hand over to a new governing body the present buildings of the Royal College of Science and Royal School of Mines, the new chemical and physical laboratories, which are approaching completion, and some adjacent acres of land on which to erect new buildings. In addition to this it is understood that the Commissioners of the $185 \mathrm{r}$ Exhibition will provide an additional building site, and that the council of the City and Guilds of London Institute will cooperate in the scheme.

The Government are prepared to provide a yearly grant about equal to the interest at $2 \frac{1}{2}$ per cent. on one million pounds sterling, and there is reason to hope that the London County Council will vote an approximately equivalent sum. In addition to this there is the munificent gift of $100,000 l$. from Messrs. Wernher, Beit, and Co., and the sum that it is expected will be provided for the equipment of the new mining and metallurgical laboratories as the central object of a national memorial to the late Sir Henry Bessemer.

In view of all these most favourable conditions the executive committee of the Guild earnestly hope that neither the question of the ultimate and final relationship of the new institution to the London University nor any other matter will be allowed to interfere with the immediate appointment of at least an organising governing body. This body might deal inter alia with the status and qualifications of the professional staff required and obtain detailed expert advice with regard to the new buildings to be erected.

Probably no more propitious time for founding a college of the kind contemplated could be offered No. I 897 , vOL. 73] 